\title{
A new kink in an old theory of carcinogenesis
}

\author{
Richmond T Prehn ${ }^{*}$ and Liisa M Prehn
}

\author{
* Correspondence: \\ prehn@u.washington.edu \\ Department of Pathology, University \\ of Washington, $5433 \mathrm{~S}$. Hudson St, \\ Seattle, WA, USA
}

\begin{abstract}
According to Berenblum's two-stage hypothesis, the first stage in carcinogenesis is the production of benign premalignant lesions. Between this initiation stage and the formation of a malignant tumor there is often a long lag phase. We propose that this lag is caused by the delay in the formation of a new and rare tumor-specific antigen, which induces an immune response that stimulates tumor growth. Such tumor-specific antigens could arise as a result of a mutator-like phenotype, which is supposedly present in the benign initial stage of carcinogenesis. According to this hypothesis, the first stage lesion provides a weakly mutagenic environment conducive to the formation of the new antigen(s). If no such new antigens appear so there is no consequent immune response, it is argued that carcinogenesis would seldom if ever ensue.
\end{abstract}

\section{Background}

The phenomenon upon which this discussion is based is nicely summarized in a paper by Brash and Cairns [1], a short section of which is reproduced here: “... Humans and animals show the same strange relationship between dose of carcinogen and time of appearance of their cancers. For example, although the incidence of lung cancer in smokers appears to be directly proportional to the number of cigarettes smoked per day [2], it is proportional to roughly the sixth power of the duration of smoking. Similarly, when rats are continuously exposed to dietary carcinogens their incidence of cancer rises as the first or second power of dose rate but as a much higher power of time $[3,4]$... smokers keep their raised rate of lung cancer for many years after they have stopped smoking [5] ... These numerous experiments suggest, therefore, that mutagenic carcinogens cause just one or two events and these (like the initial event in in vitro carcinogenesis) are then followed by steps that accumulate solely with the passage of time, driven perhaps by cell division [6]...".

In the present paper we review the probability that the frequently observed time lag in carcinogenesis is caused by the delay in the formation of a new tumor-specific antigen that, in turn, induces a tumor-stimulating immune response [7]. This tumorspecific antigen is postulated to arise as a result of a mutator-like phenotype that we postulate exists in the benign first stage of the carcinogenic mechanism $[7,8]$.

In 1949-50, when one of the present authors (RTP) joined the laboratory of the late Dr. H.B. Andervont as a fellow at the National Cancer Institute, interest was very low in all aspects of immunity in relation to cancer. In fact, in about 1956, RTP was told by the head of the National Cancer Institute that "you would be well advised to find some other topic for your investigations, many a career has been dashed on those hard

(c) 2013 Prehn and Prehn; licensee BioMed Central Ltd. This is an Open Access article distributed under the terms of the Creative Commons Attribution License (http://creativecommons.org/licenses/by/2.0), which permits unrestricted use, distribution, and reproduction in any medium, provided the original work is properly cited. 
rocks" - a vote of no confidence that led directly to RTP leaving the Institute. However, it was probably sound and proper advice at that time. After the paper of Prehn and Main in 1957 [9], followed shortly by that of the Karolinska group showing that tumorspecific immunity was possible against a methylcholanthracine-induced sarcoma even in the autologous mouse [10], the immune surveillance hypothesis became popular and has remained so to the present day.

\section{Role of the mutator phenotype in carcinogenesis}

The recent discovery of thousands of mutations in each cancer has suggested one plausible explanation for the often long delay in carcinogenesis; an ongoing mutagenic environment was probably created during an earlier exposure to mutagens (in all likelihood by the failure, via mutation, of a gene repair mechanism [8]). The resulting mutator phenotype would eventually and inevitably result in a combination of mutants that must grow as a cancer. This hypothesis accounts nicely for the lag so often seen in carcinogenesis. Other mechanisms to enhance carcinogenic accumulations have also been proposed [11-13], but the question remains - is there some further plausible explanation for the sometimes long delay beyond the time required for the mere accumulation of a carcinoma genome? Present data suggest that such an explanation may reside within the immune system.

\section{Role of the immune system in oncogenesis}

A further hypothesis that might corroborate the mutator phenotype hypothesis is a gradual decline in the strength of the immune mechanisms with age; a decline in immunity would eventually result in a cluster of mutations that would be able to grow in that weakened immune environment. Under this hypothesis, the role of time can be accounted for by the known decline in immune mechanisms in adults with increasing age [14]. It also is apparent that the incidence of most cancers rises with increasing age; it is obvious that these facts could be causally related.

We have previously published evidence suggesting that the primary role of the immune reaction in carcinogenesis is to stimulate rather than to inhibit cancer growth [15]. This stimulatory role for immunity in no way negates the idea that a decline in the immune capacity of the host may cause the eventual appearance of a cancer. Immunostimulation is dependent upon the quantitative ratio of immune reactants to tumor size; in general - up to a point - the weaker the immune mechanism, the greater the stimulatory effect on tumor growth. Thus, the weaker immunity in the aged might well be stimulatory to incipient cancers [16].

Until recently, it seemed very unlikely that immune mechanisms could affect human tumorigenesis because immune effects seemed largely confined to relatively rare carcinogen- or virus-induced cancers [17]. Hewitt was vociferous on the subject; he went so far as to publish his failed attempt to demonstrate the induction of immune inhibition in seven different spontaneous cancers in mice; the only effect of his immunization attempts was that, in all seven cases that he tested, the tumors grew better in the presumptively immunized syngeneic mice than in the non-immunized controls [17]! This same stimulation of the growths of implants in specifically immunized recipients was confirmed using a new set of spontaneous mouse tumors by 
workers in Argentina [18]. Hewitt suggested that his own results were due to a lack of specific antigens on his spontaneously-derived tumors. However, we interpreted the stimulation as showing the presence of low levels of tumor-specific antigens that produced weakly stimulatory rather than inhibitory concentrations of immune reactants. As already mentioned, in 1972 RTP had made the counterintuitive observation that small numbers of spleen cells from tumor immune mice could, when mixed with the target tumor, sped rather than inhibited the growth of the mixture when it was implanted into immunodepressed syngeneic recipients [15]. Apparently the immune system is subject to some form of hormesis because larger quantities of immune cells, when used in like manner, markedly inhibited the cancer's growth [19]. This observation has, in essence, been confirmed by many others [20-22] and is central to the present formulation.

\section{The two-stage hypothesis}

In the 1950s, a major topic of discussion was the idea put forth by Friedewald and Rous [23], and further developed by Berenblum and Shubic [24], that carcinogenesis could be divided into two quite different and distinct stages. There has been much subsequent argument about the phenomenon, but it is widely agreed that it is real, at least in many situations. The essence of the proposal is that if a sub-carcinogenic dosage of a carcinogen is followed by one of a number of non-carcinogenic irritants, cancers may then be produced; classically, a subcarcinogenic dosage of a hydrocarbon carcinogen (the initiator), followed by paintings of the same skin area with the non-carcinogenic irritant, croton oil (the promoter). The initiating effect was shown to be very long lasting. However, reversal of the application sequence yielded no observable carcinogenic effect in most studies. Students in our laboratory devised another method that used skin grafting as a promoter $[25,26]$.

According to Berenblum's two-stage hypothesis [24], the first stage is the production of benign premalignant lesions. We postulate that the second stage is a small immune response to rare new antigens on a previously benign first stage (papilloma?) cell, which stimulates that cell to multiply as a malignant tumor. According to this hypothesis, the papilloma or other benign first stage lesion would itself provide an environment conducive to the formation of new antigens (a weakly mutagenic environment); in the absence of such new antigens and the consequent immune response to them, carcinogenesis would, according to the work of Andrews, seldom if ever occur [7,26]. Andrews's two stages produced no cancers but many regressing benign papillomas in mice that had been maximally immunodepressed [27]. To achieve an immunological cancer cure, one would apparently have to supply the patient with a large enough immune reaction to inhibit rather than stimulate tumor growth. Alternatively, perhaps one could inhibit tumor growth by drastically reducing the immune reaction.

\section{Conclusions}

Cancer formation probably depends upon a new antigenicity that arouses a weak but stimulatory immunity to a new tumor antigen - an antigen that arose as a kink in the benign cells that had been induced in the first stage of the two stage carcinogenic process [7]. This kinked two stage hypothesis accounts rather neatly for the time lag in the carcinogenic mechanism. 
The reality of the phenomenon of immunostimulation of cancer by relatively small quantities of immunity is now well established [20-22], though the mechanism of this stimulatory effect remains obscure. A possible explanation may reside in work of Rubin showing that cellular growth is inhibited by interactions with surrounding normal cells [28]; perhaps a small amount of immunity can interfere with this inhibitory reaction and thus appear to stimulate [29].

Possible mechanisms of immunostimulation have also been discussed by Parmiani [30]. We acknowledge that immunity is a very complex phenomenon; many diferent types of immune cells have been described and, although in this paper we have emphasized the overriding importance of the quantitative relationship between the target and immunity, we admit that among the complexities of the response are individual elements that may be stimulatory while others are inhibitory to tumor growth [31-33]. It seems possible to us that whether an immune effector becomes a morphologically recognizable inhibitor or stimulator might even be determined, at least in part, by the afore mentioned quantitatve relationship, albeit that we have little evidence for such an effect.

It seems probable that selection might, in most cases, keep a weak immune reaction at nearly optimal levels for tumor growth indefinitely. However, the fact that a depressed level of immunity increases the growth of some tumor types in humans $[34,35]$ suggests that such tumors may not have originally enjoyed the optimal immunity for the fastest possible tumor growth.

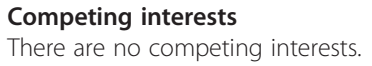

Authors' contribution

Both authors were equally responsible for all parts of the M.S. Both authors read and approved the final manuscript.

\section{Acknowledgement}

The authors express their thanks to Drs. L Loeb and P Agutter for critically reading the M.S. prior to its submission.

Received: 17 December 2012 Accepted: 12 February 2013

Published: 18 February 2013

\section{References}

1. Brash D, Cairns J: The mysterious steps in carcinogenesis. Br J Cancer 2009, 101:379-380.

2. Zaridze D, Peto R: Influence of dose and duration of smoking on lung cancer rates. Tobacco: Major international health hazard IARC Sci Publs. Lyon 1986, 74:23-33. 33eds.

3. Druckrey H: Quantitative aspects in chemical carcinogenesis. UICC Monogr Ser 1967, 7:61-79.

4. Peto R, Gray R, Brantom P, Grasso P: Dose and time relationships for tumor induction in the liver and esophagus of 4080 inbred rats by chronic ingestion of $\mathrm{N}$-nitrosodiethylamine or $\mathrm{N}$-nitrosodimethylamine. Cancer Res 1997, 51:6452-6469.

5. Halpern MT, Gillespie BW, Warner KE: Patterns of absolute risk of lung cancer mortality in former smokers. J Natl Cancer Inst 1993, 85:457-464.

6. Linell E: On the tumour promoting effect of a single mechanical trauma. Acta Path Microbio/ Scand 1947, 71(Suppl):1-110.

7. Prehn RT, Prehn LM: Is an immune reaction required for malignant transformation and cancer growth? Cancer Immunol Immunother 2012, 61:863-968.

8. Schmitt MW, Prindle MJ, Loeb LA: Implications of genetic heterogeneity in cancer. Ann NY Acad Sci 2012, 1267:110-116.

9. Prehn RT, Main JM: Immunity to methylcholanthrene-induced sarcomas. J Natl Cancer Inst 1957, 18:769-778.

10. Klein G, Sjögren HO, Klein E, Hellström KE: Demonstration of resistance against methylcholanthrene-induced sarcomas in the primary autochthonous host. Cancer Res 1960, 20:1561-1572.

11. TIsty TD: A twist of cell fate. Cell Stem Cell 2011, 8:126-127.

12. TIsty TD, Coussens LM: Tumor stroma and regulation of cancer development. Annu Rev Pathol 2006, 1:119-150.

13. Weiland A, Roswall P, Hatzihristides TC, Ostman A, Strell C: Fibroblast-dependent regulation of the stem cell properties of cancer cells. Neoplasma 2012, 59:719-727.

14. Aoki T, Teller MN: Aging and carcinogenesis. 3. Effect of age on isoantibody formation. Cancer Res 1966, 26:1648-1652.

15. Prehn RT: The immune reaction as a stimulator of tumor growth. Science 1972, 176:170-171. 
16. Outzen HC: Development of carcinogen-induced skin tumors in mice with varied states of immune capacity. Int J Cancer 1980, 26:87-92

17. Hewitt HB, Blake ER, Walder AS: A critique of the evidence for active host defense against cancer based on personal studies of 27 murine tumors of spontaneous origin. Br J Cancer 1976, 33:241.

18. Bruzzo J, Ruggiero RA, Chiarella P: On the immunostimulatory hypothesis of cancer. Medicina (Buenos Aires) 2011, 71:509-513.

19. Calabrese EJ: Hormesis and medicine. Br J Clin Pharmacol 2008, 66:594-617.

20. Fidler IJ: Immune stimulation-inhibition of experimental cancer metastases. Cancer Res 1974, 34:491-498.

21. Fidler IJ: In vitro immune stimulation-inhibition to spontaneous canine tumors of various histologic types. J Immunol 1974, 112:1051-1060

22. Prehn RT, Prehn LM: The autoimmune nature of cancer. Cancer Res 1987, 47:927-932.

23. Friedewald WF, Rous P: The initiating and promoting elements in tumor production. $J$ Exp Med 1944, 80:101-126.

24. Berenblum I, Shubik P: The role of croton oil applications, associated with a single painting of a carcinogen, in tumour induction of the mouse's skin. Br J Cancer 1947, 1:383-391.

25. Prehn RT: Immunostimulation and immunoinhibition of premalignant lesions. Theor Biol Med Model 2007 4:6-10.

26. Lappé MA, Prehn RT: Immunologic surveillance at the macroscopic level: Nonselective elimination of premalignant skin papillomas. Cancer Res 1969, 29:2374-2378.

27. Andrews EJ: Evidence of the nonimmune regression of chemically induced papillomas in mouse skin. J Nat Cancer Inst 1971, 47:653-665.

28. Rubin $\mathrm{H}$ : Cell-cell contact interactions conditionally determine suppression and selection of the neoplastic phenotype. Proc Natl Acad Sci U S A 2008, 105:6215-6221.

29. Prehn RT: Does the immune reaction cause malignant transformation by disrupting cell-to-cell or cell-to -matrix communications? Theor Biol Med Model 2007, 4:16.

30. Parmiani G, Maccalli C: The early antitumor immune response is necessary for tumor growth Revisiting Prehn's hypothesis in the human melanoma system. Oncoimmunology 2012, 1:930-934.

31. DeNardo DG, Andreu P, Coussens LM: Interactions between lymphocytes and myloid cells regulate pro- versus anti-tumor immunity. Cancer Metastasis Rev 2010, 29:309-331.

32. Enderling H, Hahnfeldt P, Hlatky L, Almog N: Systems biology and tumor dormancy: Linking biology and mathematics on multiple scales to improve cancer therapy. Cancer Res 2012, 72:2172-2175.

33. DeNardo DG, Brennan DJ, Rexhepaj E, Ruffell B, Shiao SL, Madden SF, Gallagher WM, Wadhwani N, Keil SD, Junaid SA, Rugo HS, Hwang ES, Jirström K, West BL, Coussens LM: Leukocyte complexity predicts breast cancer survival and functionally regulates response to chemotherapy. Cancer Discov 2011, 1:54-67.

34. Ioachim HI: The opportunistic tumors of immune deficiency. Adv Cancer Res 1990, 54:301-317.

35. Stewart T, Henderson R, Grayson H, Opelz G: Reduced incidence of rectal cancer, compared to gastric and colonic cancer, in a population of 73,076 men and women chronically immunosuppressed. Clin Cancer Res 1997, 3:1-5.

doi:10.1186/1742-4682-10-12

Cite this article as: Prehn and Prehn: A new kink in an old theory of carcinogenesis. Theoretical Biology and Medical Modelling 2013 10:12.

\section{Submit your next manuscript to BioMed Central and take full advantage of:}

- Convenient online submission

- Thorough peer review

- No space constraints or color figure charges

- Immediate publication on acceptance

- Inclusion in PubMed, CAS, Scopus and Google Scholar

- Research which is freely available for redistribution

Submit your manuscript at www.biomedcentral.com/submit 